\title{
A Review of Three-Phase Grid-Connected with Solar PV power based using MPPT Controller
}

\author{
Prashant Singh Bijor \\ Research scholar, ME (HVPS) Jabalpur Engineering College, Jabalpur (M.P) 482011, India \\ Dr. A.K. Sharma
}

Professor, Department of Electrical Engineering, Jabalpur Engineering College, Jabalpur (M.P) 482011, India

\begin{abstract}
Currently, solar energy is one of the renewable energy that the Republic of Liberia has been blessed with. Solar energy is environmentally friendly and very simple to apply compared to alternative sources of renewable energy. Solar energy often meets the direct desires of electricity with the help of a photovoltaic system and power electronic devices. With the rapid use of the photovoltaic panel, the generated energy is transferred to the grid due to the limitations of value and useful life of the energy storage system. the design and analysis of a grid-connected three-phase photovoltaic electrical converter is well discussed in this article.
\end{abstract}

Keywords- Photovoltaic, MPPT, Proportional Integral (PI), MatLab.

\section{Introduction}

The inverter supplies DC power to AC power and is useful for powering electronic and electrical instrumentation rated at AC mains voltage. Before developing the inverter, a mathematical model for the photovoltaic system not to mention the proportional-integral controller and perturbations and observing the MPPT formula were designed to access the varied characteristics of the photovoltaic module About $75 \%$ of the photovoltaic systems installed in the world are connected to the network [1]. In the grid-connected photovoltaic system, the DC-AC converters (inverters) need to perform the grid interconnection, inverting the DC current coming from the PV array into a sine waveform synchronized with the electrical grid [2, 3]. Furthermore, the DC-AC converter is used to stabilize the DC bus voltage to a specific value as the output voltage of the PV array varies with temperature, irradiance and the effect of MPPT (maximum power point tracking). The photovoltaic array converts the radiation into voltage and also the electrical converter converts the DC power into AC power, which is fed to the grid. The technical term for the electrical converter is "grid connected 


\section{International Journal of Scientific Research in Engineering and Management (IJSREM)}

inverter". The grid connected inverter is connected to the electrical grid and is used to convert AC power to DC power.

\section{Literature review}

The demand for electricity has been growing proportionally to population growth and also due to rapid industrialization [1]. To bridge the gap between demand and supply, additional fossil fuels need to be burned, leading to various disadvantages such as rapid depletion of fossil fuels, environmental pollution, greenhouse effect, acid rain, global warming, etc. fossil fuels are replaced by renewable energy sources (RES). The various RES available are solar energy, wind energy, tidal energy, geothermal energy, energy from small hydro, biomass energy, etc., among the various RES available; solar energy has an advantage over other RES [2-5].

The solar photovoltaic (PV) system converts solar energy into electrical energy. Photovoltaic system has several advantages such as required input, i.e. solar energy is available for free, less dependence on oil, gas, coal for electricity production, therefore, no pollution will be produced as there are no moving parts. maintenance is not required, in the long run there will be high returns for the amount invested in the photovoltaic system [6-7].

The disadvantages associated with the photovoltaic system is that the required solar energy will not be available 24 hours a day, solar panels require additional equipment such as converters, inverters, charge controllers, the land required for installing the solar panels will be higher, the cost of Installation of The photovoltaic system is high, solar panels have an efficiency in the range of $15 \%$ to $25 \%$. As the advantages of the photovoltaic system dominate the disadvantages, photovoltaic systems are more used in the generation of electrical energy. The photovoltaic system can be used to supply local load or it can also be directly connected to the grid [8-9]. The first method of supplying electrical energy to the load is called standalone operation mode and the later method of supplying power to the grid is called grid connected operation mode [10]. 


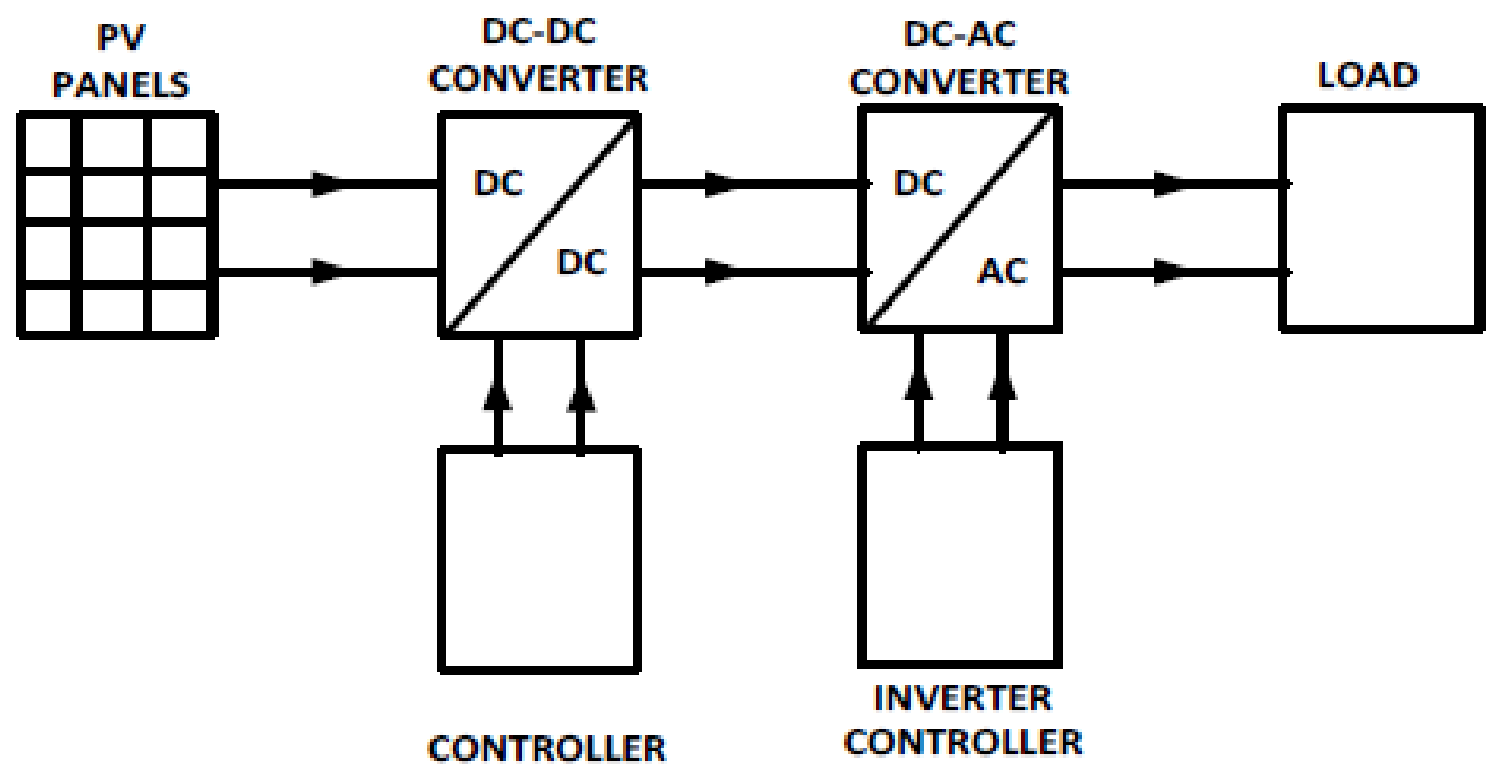

Figure 1 PV system in standalone mode of operation

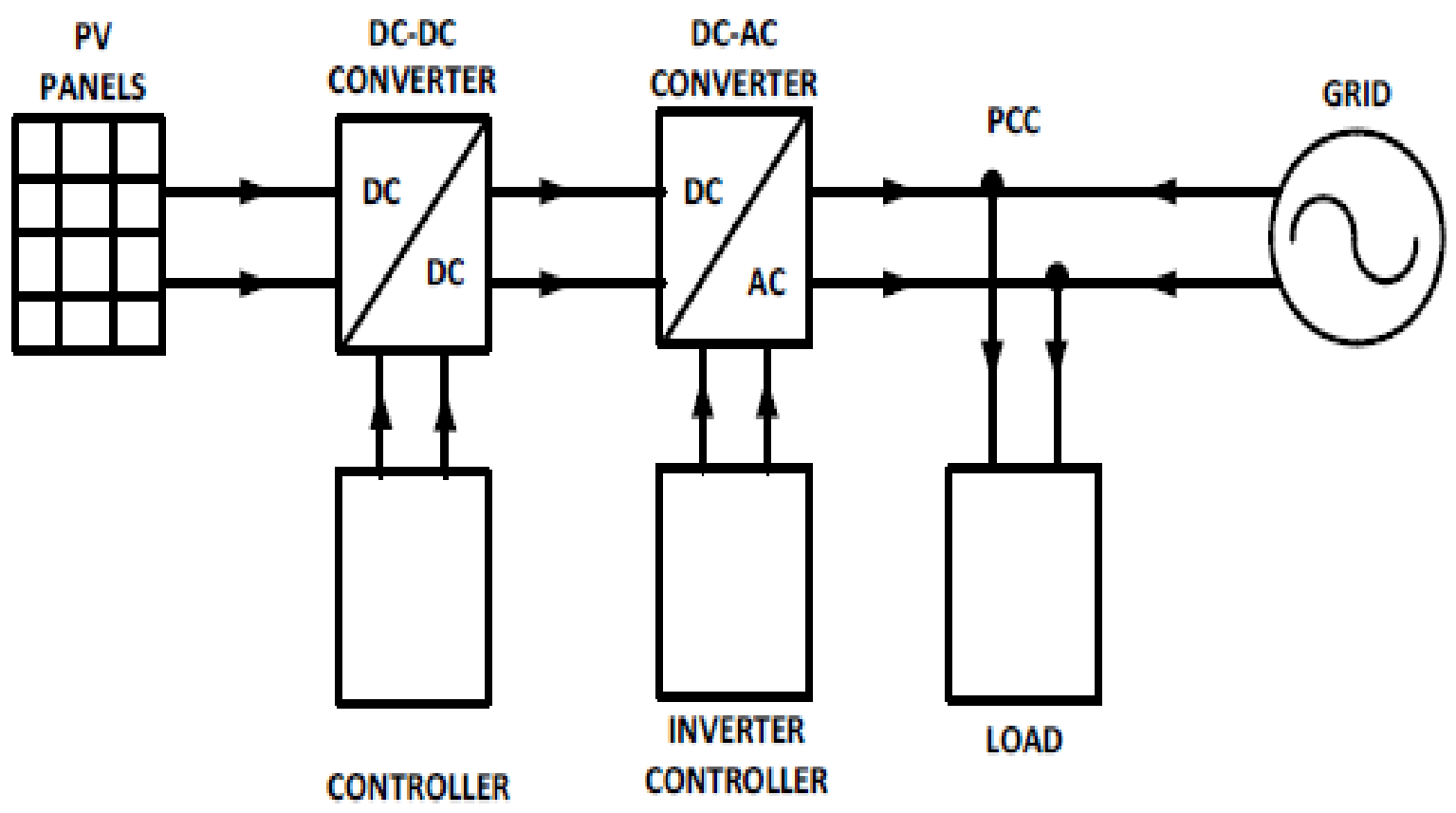

Figure 2 PV system in grid connected mode of operation 


\section{Grid-Connected Inverter}

The grid-connected three-phase power converter completes the power supply where power is converted from DC to AC. To appreciate this, the energy generated by the photovoltaic system is regenerated from DC to $\mathrm{AC}$ by an electrical converter connected to the grid. Synchronizes current and frequency according to national or local network. The output voltage is initialized from the mains so that it is slightly higher than the mains voltage for additional voltage. "The three-phase grid-connected electrical converter is considered exclusively for grid-connected applications that do not require cooperative energy storage systems." The three-phase power converter is commonly used for high power applications, although the project is intended to encourage individual households to use the grid-connected three-phase electrical converter.

\section{Problem Statement}

The 1989 and 2003 war severely affected Liberia's social and economic development. The influx of donor partners and international communities has notably not significantly improved the social and economic situation of the Liberian people. However, like many countries in Africa, many other developing countries have a terrible energy sector. Liberia as an African nation currently has a population of 4.8 million. Current energy services are supported by hydroelectric machines and diesel oil production.

\section{PV System}

The various elements of the photovoltaic system are photovoltaic panel, power conditioning devices, i.e. a DC-DC converter, MPPT controller, DC-AC converter, i.e. an inverter, filter. The output voltage generated is variable and low, a DC-DC boost converter increases the generated DC voltage to the required voltage level. The output photovoltaic power generated depends on weather conditions. There is a single operating point in the I-V curves, P-V curves where the output power generated by the photovoltaic panels will be maximum and this is represented by Pmax. The MPPT controller tracks this unique operating point and operates the PV system at this point. 


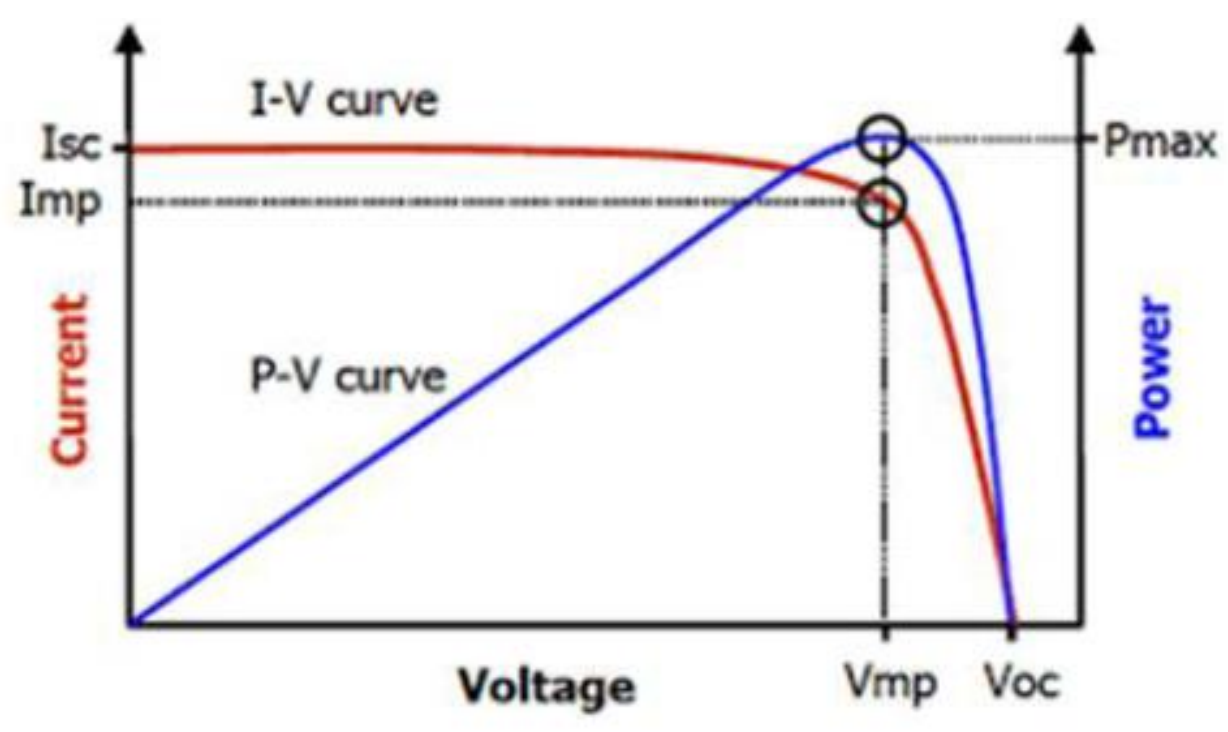

Figure 3 I-V curve, P-V curve of a PV cell

DC-AC converter i.e. an inverter converts the increased DC voltage into AC voltage and this converted voltage can be supplied to the load AC loads or it can be connected to the mains. Filters are used to eliminate harmonics at the inverter output and provide pure $\mathrm{AC}$ power.

\section{Integrated system design and Configuration}

An inverter connected to the three-phase grid is currently considered to be the most reliable means of transmitting DC power to an AC grid. An inverter basically converts DC power to AC. The system is basically composed of a 50kW solar photovoltaic system, boost converter with Perturb and Observe MPPT model, threephase inverter and power grid. System AC voltage is 400 volts, but for inverter safety factor and voltage variation in practical application, we consider twenty percent (20\%) of system voltage to quantify DC-DC boost converter and inverter. As you can see, the inverter has a separate control. For the photovoltaic array, the DC DC boost converter is used to increase the DC voltage required for the input voltage of the inverter. This is done with the help of the P\&O MPPT algorithm.

\section{Conclusion}

The current voltage at this radiation intensity and the ambient temperature are plotted for both operating modes. The $\mathrm{P} \& \mathrm{O}$ method of maximum power point tracking strategies is used in this work and is simulated. The boost DC/DC converter, inverter, is part of the photovoltaic system. The PI controller is used for voltage regulation of a grid-connected three-phase photovoltaic system. The controller action is explained. 


\section{International Journal of Scientific Research in Engineering and Management (IJSREM)}

\section{Reference}

[1] L. Malesani, "Current control techniques for three-phase voltage-source pwm converters: a survey," IEEE Transactions on Industrial Electronics, vol. 45, no. 5, pp. 691-703, 1998.

[2] B. Yu, I. A. Gadoura, L. Chang, and M. Ghribi, "A novel DSP-based current-controlled PWM strategy for single phase grid connected inverters," IEEE Transactions on Power Electronics, vol. 21, no. 4, pp. 985-993, 2006.

[3] E. N. Costogue and S. Lindena, "Comparison of candidate solar array maximum power utilization approaches," in Proceedings of the Intersociety Energy Conversion Engineering Conference, pp. 1449-1456, 1976.

[4] Wu, B., Leon, J.I., Rodriguez, J., and Franquelo, L.G., "Cascaded H-bridge multilevel converter multistring topology for large scale photovoltaic systems," IEEE Industrial Electron. Int. Symp., Gdansk, Poland, Jun. $27-$ 30, 2011, pp. 1837- 1844.

[5] H. Patangia and D. Gregory, "An efficient cascaded multilevel inverter suited for PV application," 35th IEEE Photovolt. Spec. Conf., Honolulu, HI, Jun. 20-25, 2010, pp. 2859-2863.

[6] Rahim, Nasrudin Abdul, Senior Member, and Jeyraj Selvaraj, 'A Novel Multi-String Five-Level PWM, Inverter for Photovoltaic Application', 2011 IEEE International Electric Machines \& Drives Conference (IEMDC)

[7] R. Lai, F. Wang, R. Burgos, Y. Pei, D. Boroyevich, B. Wang, T. A. Lipo, V. D. Immanuel and K. J. Karimi, "A systematic topology evaluation method for high density three-phase pwm ac-ac converter", IEEE Transaction on Power Electronics, Vol. 23, NO. 6, November 2008.

[8] E. Rhyne, K. Smith and D. Bratton, “A 3-phase inverter using aferroresonant transformer assembled on a single laminated core”, Telecommunications Energy Conference, 14th International 4-8 Oct. 1992.

[9] Abdul Hamid, Md. Iqbal Hossain, Ummal Husnaeen and Bin Yousuf, Design and Development of a Grid Tied Solar Inverter, International Conference on Informatic, Electronics and Vision, 2012 [10] Mowei, Loh Poh Cliang, and Ding Yi, Optimal Design of two Level Inverters, IEEE IPEC, 2010 